\title{
WikiLeaks as Rubicon and Zeitgeist
}

How the Advance of Digital Era Affects Transparency of Power

Stanislav L. Tkachenko

On April 11, 2019, London police arrested WikiLeaks founder Julian Assange at the Ecuadorian Embassy. He was denied further asylum. Today, the fuss caused by the publication of thousands of classified documents in the early 2010s is almost forgotten, but Assange has already entered the history of diplomacy.

If we exaggerate a little, we can say that the whole history of diplomacy can be divided into two periods: "before" and "after" WikiLeaks, because never before has there been such a sweeping release of documents describing the routine, practice and style of diplomacy, as well as the extent of the interaction between diplomats, special services, politicians and government organizations. When the scale of these secretive operations and the facts themselves, such as the U.S. presence in Iraq or how American diplomats watch Russia, were revealed seven years ago, it was nothing short

Stanislav L. Tkachenko is a Visiting Professor at the Research Centre for the Economies and Politics of Transitional Countries at Liaoning University. Originally published by the International Valdai Discussion Club at: http://valdaiclub.com/a/highlights/wikileaks-asrubicon-and-zeitgeist/

DOI: 10.31278/1810-6374-2019-17-2-131-133 
of a revolution. For diplomacy, this was a defining moment, and the way the U.S. reacted to Assange and Snowden shows that it wants to preserve an aura of secrecy which is no longer possible in the 21st century. Washington's response could be likened to Don Quixote battling the windmills.

As for the current situation, Assange seems to have had bad luck. Snowden was luckier-he sought asylum in a truly sovereign country. Perhaps Ecuador is a radical country, and, like any other Latin American country, once every five years or so it shows the U.S. its temper and makes harsh statements, but later everything returns to normal. At first, Ecuador was persuaded and frightened, and now Julian Assange has been in fact exchanged for an IMF loan of several billion dollars. This was the price of Ecuador's sovereignty.

In any event, it can hardly be argued that he could not change anything. If we try to understand why a bevy of unformatted politicians like Trump, Macron, or most recently Zelensky in Ukraine were able to come to power, we can conclude that a transformation is at hand, from the traditional era into a modern digital one. The case of WikiLeaks is unlikely to serve as the cornerstone for new practices in international relations, but it has played a role. If it hadn't been Assange, someone else would have done it.

Another thing-and this is a task for historians-is understanding his personality. Of course, he is an idealist, he leans heavily to the left and can even be considered an outright "leftist," and in this sense he has to discover to what extent his personal political views correspond to the practice he tried to implement: in fact, this is a fight between censorship and the free, open publication of documents. No matter how we treat Assange, he acted in the spirit of the current Zeitgeist.

He used modern technology to make it clear to governments that if earlier they could conceal, say, $10 \%$ of their international and even domestic activity, now they can hide ten times less.

Proceeding from this, the transparency of power lespecially in international relations, where this level was already high) has increased further. 
If the authorities lack the necessary wherewithal, the new Assanges will be incarcerated, shot or die in dubious car accidents. If they develop this wherewithal, they will take into account the whistleblower factor, practice more discretion and rely less on the methods the Americans used in Iraq or Russia. Whether the institutional power of the state becomes more "democratic" or "civilized" remains hard to say. One way or another, WikiLeaks and Julian Assange have already made history regardless of what happens to them or what will happen. 